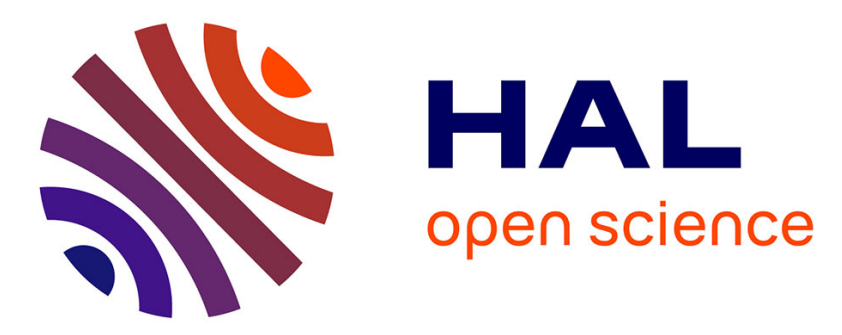

\title{
The five shades of oleylamine in a morphological transition of cobalt nanospheres to nanorods
}

\author{
Arthur Moisset, Alexandre Sodreau, Anthony Vivien, Caroline Salzemann, \\ Pascal Andreazza, Suzanne Giorgio, Marc Petit, Christophe Petit
}

\section{To cite this version:}

Arthur Moisset, Alexandre Sodreau, Anthony Vivien, Caroline Salzemann, Pascal Andreazza, et al. The five shades of oleylamine in a morphological transition of cobalt nanospheres to nanorods. Nanoscale, In press, 10.1039/D1NR01502H . hal-03269446

\section{HAL Id: hal-03269446 \\ https: / hal.sorbonne-universite.fr/hal-03269446}

Submitted on 24 Jun 2021

HAL is a multi-disciplinary open access archive for the deposit and dissemination of scientific research documents, whether they are published or not. The documents may come from teaching and research institutions in France or abroad, or from public or private research centers.
L'archive ouverte pluridisciplinaire HAL, est destinée au dépôt et à la diffusion de documents scientifiques de niveau recherche, publiés ou non, émanant des établissements d'enseignement et de recherche français ou étrangers, des laboratoires publics ou privés. 


\title{
The five shades of oleylamine in a morphological transition of cobalt nanospheres to nanorods
}

\begin{abstract}
Arthur Moisset, ${ }^{\ddagger a}$ Alexandre Sodreau, ${ }^{\text {tb }}$ Anthony Vivien, ${ }^{\mathrm{a}, \mathrm{b}}$ Caroline Salzemann, ${ }^{\mathrm{a}}$ Pascal Andreazza, ${ }^{\mathrm{c}}$ Suzanne Giorgio, ${ }^{\text {A }}$ Marc Petit, ${ }^{* b}$ Christophe Petit*a

Understanding of cobalt nanorods' (Co NRs) formation still remains challenging when it comes to enhancing their anistropic properties applicable in magnetic or catalytic areas. Herein, we propose a mechanism for the morphological transition from spherical cobalt nanoparticles (NPs) to Co NRs overtime (9h) in a mixture of $\left[\mathrm{CoCl}\left(\mathrm{PPh}_{3}\right)_{3}\right]$ and oleylamine $(\mathrm{OAm})$. In literature, we described how spherical Co NPs are synthesized via a disproportionation process. Based on in-situ and pseudo in-situ observations, two steps of this unique mechanism is characterized first by the dissolution of the spheres and then the regrowth in rods' shape in presence of an OAm template. Furthermore, ex-situ experiments show that these steps are the result of interdependent reactions occuring between Co NPs, cobalt (II) and OAm. The latter, plays numerous roles in this synthesis: surfactant, disproportionation promoter, hydrogen source allowing the reduction of cobalt (II) complexes; its ammonium salt derivative is involved in oxidative etching of Co NPs and it promotes the anisotropic growth in NRs. These coupling actions of reduction and etching generate two cobalt reservoirs of nuclei under thermodynamic conditions.
\end{abstract}

\section{Introduction}

Nowadays plenty of innovative applications call for nanoobjects presenting a controlled size, shape, and crystallinity. In this regard, the continuous advances in colloidal synthesis of nanomaterials ${ }^{1}$ highly contribute to the establishment of a large library of well-defined objects. ${ }^{2-5}$ However, the understanding of the mechanical steps leading to the shape control of these objects still remains challenging. Indeed many physicochemical parameters can highly influence the reaction. ${ }^{6}$ This is particularly true for NRs syntheses, which have been intensely studied in order to enhance their anisotropic properties through this shape control. Undeniably, Co NRs are one of the prime examples of magnetic capacity improvement thanks to an anisotropic shape 7,8 which, added to the high magnetic moment of cobalt, 9 promotes their use in magnetic area such as electronic devices ${ }^{10}$ or high-density recording devices. ${ }^{11}$ Moreover, Co NRs and more generally hexagonal close packed (hcp) cobalt nano-objects have shown their higher ability to catalyze chemical reactions such as Fisher-Tropsch ${ }^{12}$ or acceptor less dehydrogenation compared to fcc and $\varepsilon$ structures. ${ }^{13}$ The

\footnotetext{
a. Sorbonne Université, CNRS, MONARIS, UMR 8233, 75005 Paris, France

Email : christophe.petit@sorbonne-universite.fr

b. Sorbonne Université, CNRS, Institut Parisien de Chimie moléculaire, UMR 8232 75005 Paris, France.

Email : marc.petit@sorbonne-universite.fr

c. Université d'Orléans, CNRS, Interfaces Confinement Matériaux et Nanostructures, UMR 7374, 45100 Orléans, France

d. Aix-Marseille Université, CNRS, CINAM, Centre Interdisciplinaire de Nanoscience de Marseille, UMR 7325, 13288 Marseille, France +Electronic Supplementary Information (ESI) available. Se DOI: $10.1039 / x 0 x x 00000 x$
}

¥These authors contributed equally to this work. mechanistic aspects of the synthesis of the nanorods are not always clearly identified depending on the metal; ${ }^{14-16}$ and, in the specific case of cobalt nanorods only two different mechanistic pathways have been reported: i) An Organometallic pathway (Scheme 1, orange square), with the reduction of coordinated cobalt complexes in presence of fatty carboxylic acid and amino ligands mixture under hydrogen pressure at $150^{\circ} \mathrm{C}$, the proposed mechanism identified three main steps: a fast nucleation, then a fast growth with the reduction of cobalt complex and the epitaxial attachment of the nuclei completely formed through a slow ripping by the coalescence of NRs once the full reduction is completed; ${ }^{17-19}$ and, ii) The Polyol process (Scheme 1, green square), with the reduction of cobalt carboxylate salts via a polyol process in presence of a small amount $\left[\mathrm{RuCl}_{3}\right]$ or $\left[\mathrm{IrCl}_{3}\right](2.5 \%)$ and $\mathrm{NaOH}$ at $180^{\circ} \mathrm{C}$, during the reaction, it was established that an initial formation of noble metal seeds, the nucleation step, is separated to a later reduction of cobalt precursors and induced a directed growth leading by the crystalline structure of the Ru/Ir seeds. ${ }^{20-22}$ For the organometallic pathway and polyol process, the favorable adsorption of carboxylate ligand at the $\{11 \overline{2} 0\}$ facets induce an easier attachment of cobalt nuclei along the $c$ axis. ${ }^{19,23}$ Additionally, an Oswald ripening may be required to increase the homogeneity of NRs.

Beyond its chelating properties involved in the passivation of nano-objects and its reducing action through the $\mathrm{C}-\mathrm{N}$ bond cleavage, ${ }^{24}$ we previously established that oleylamine (OAm) was able to perform a ligand exchange on the starting complex $\left[\mathrm{CoCl}\left(\mathrm{PPh}_{3}\right)_{3}\right]$ resulting in the formation of: $\left[\mathrm{CoCl}\left(\mathrm{PPh}_{3}\right)_{3}\right.$ $\left.n(\mathrm{OAm})_{n}\right]$ and the promotion of a disproportionation process 


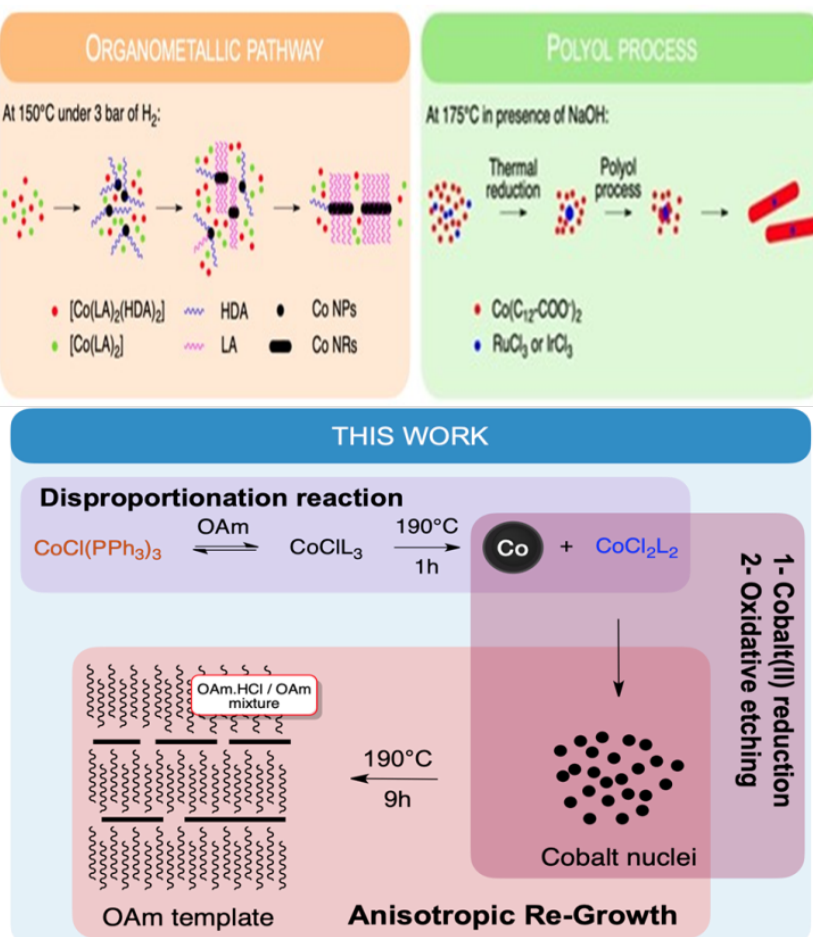

Scheme 1. Chemical process to the formation of Co NRs

leading to Co NPs. ${ }^{25}$ Moreover, when the reaction time was extended from $1 \mathrm{~h}$ to $10 \mathrm{~h}$, the initial spherical NPs were substituted by NRs suggesting that the first redox reaction was followed by a second mechanism. ${ }^{26}$ Interestingly, this morphological transition did not require any additives, any noble metal seeds or surfactants mixing to control their growth. Herein, only a mixture of cobalt (I) precursor and OAm was used.

In this work, an original mechanism of the morphological transition from spherical hcp-Co NPs to hcp-Co NRs was reported (Scheme 1, blue square). To facilitate the mechanistic understanding, in-situ methods were set up to identify the phenomena involved: i) E-TEM (Environmental-Transmission Electronic Microscopy) monitored the formation of Co NRs inside an observation cell ${ }^{27,28}$ giving real time data with atomic resolution, ii) SAXS (Small Angle X-Ray Scattering) ${ }^{29}$ can also be used as a "pseudo in-situ analysis" to report the size, shape and polydispersity evolution of the NRs by collecting periodically samples over time and by allowing to collect data about 2D and 3D organization of the particles. ${ }^{30,31}$ It was observed that the regrowth into rod shape due to textured OAm succeeded the dissolution of NPs. Here we pointed out the important key roles of OAm in five different ways: as a disproportionation promoter, a surfactant, a hydrogen source, and its ammonium salt for the etching and for the anisotropic growth in NRs. Additionally, further experiments shed light the catalytic role of the spherical Co NPs, formed after $1 \mathrm{~h}$ of reaction.

\section{Results and discussion}
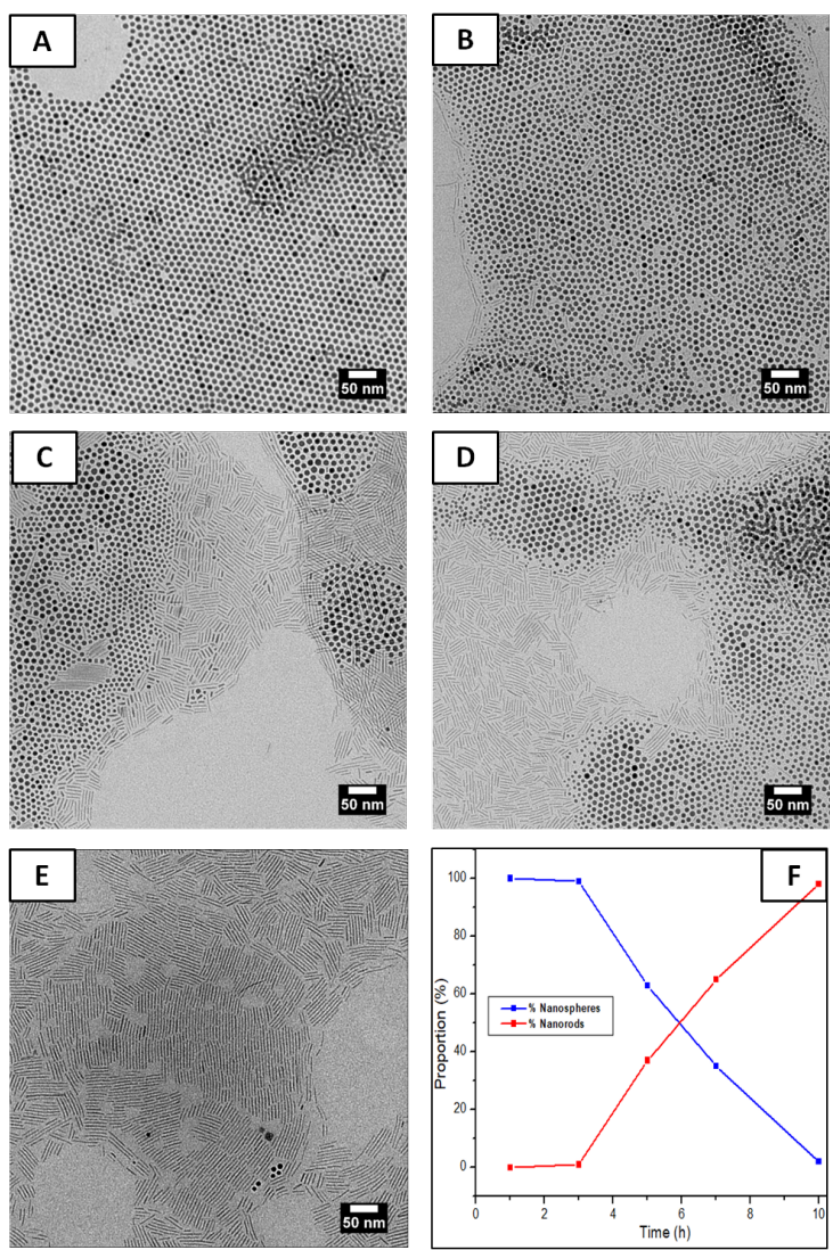

Fig. 1 Co NPs synthesis with $10 \mathrm{ml}$ of OAm. Samples are collected $(1 \mathrm{~mL})$ and washed with EtOH ( $3 \mathrm{~mL}$ ) at $1 \mathrm{~h}(\mathrm{~A}), 3 \mathrm{~h}(\mathrm{~B}), 5 \mathrm{~h}(\mathrm{C}), 7 \mathrm{~h}(\mathrm{D})$ and $10 \mathrm{~h}(\mathrm{E})$. Proportion of spherical Co NPs and Co NRs over time $(F)$.

To understand this morphological transition from spherical NPs to NRs, a kinetic study was first made using Transmission Electronic Microscopy (TEM). Samples were collected in the solution at $1 \mathrm{~h}, 3 \mathrm{~h}, 5 \mathrm{~h}, 7 \mathrm{~h}$ and $10 \mathrm{~h}$ then washed and re-dispersed in solution; statistical studies of the objects were operated (Fig. 1, Table 1). After $1 \mathrm{~h}$, homogeneous spherical NPs were collected and a blue-purple supernatant cobalt (II) formed after disproportionation ${ }^{25}$ was observed; at $3 \mathrm{~h}$, the first NRs were visible beside every nanosphere aggregates; at $5 \mathrm{~h}$ and $7 \mathrm{~h}$, more NRs were present in the solution; finally at $10 \mathrm{~h}$, only NRs remained in the media and it is noteworthy to mention that after $10 \mathrm{~h}$ the supernatant is now colorless suggesting the disappearance of the cobalt (II).

The observation of the reaction media brought out the disappearance of the disproportionation reaction product, $\left[\mathrm{CoCl}_{2}\left(\mathrm{PPh}_{3}\right)_{2-n}(\mathrm{OAm})_{n}\right]$ (blue-purple in solution), thus suggesting a reduction of this cobalt (II) intermediate. Moreover, contrary to the mechanism described by Chaudret et al. the smaller width of nanorods $(2-3 \mathrm{~nm})$ compared to the diameter of spherical NPs $(9.2 \mathrm{~nm})$ could exclude the formation of rods by the aggregation of the spherical NPs (Fig. S1 $\dagger$, Table 1). Furthermore, the diameter of the remaining spherical Co NPs decreased over time in favor of the increase of the length of Co NRs; the polydispersity increased as well, 
Table 1 Data of TEM images of the Co NPs synthesis with $10 \mathrm{ml}$ of OAm.

\begin{tabular}{|c|c|c|c|c|c|}
\hline & $1 \mathrm{~h}$ & $3 h$ & $5 h$ & $7 \mathrm{~h}$ & $10 \mathrm{~h}$ \\
\hline $\begin{array}{c}\text { Diameter } \\
\text { Sphere (nm) }\end{array}$ & $\begin{array}{c}9.2 \pm \\
0.9 \\
(10 \%)\end{array}$ & $\begin{array}{c}7.9 \pm \\
1.6 \\
(20 \%)\end{array}$ & $\begin{array}{c}7.3 \pm \\
2.0 \\
(27 \%)\end{array}$ & $\begin{array}{c}7.1 \pm \\
2.0 \\
(28 \%)\end{array}$ & $x$ \\
\hline $\begin{array}{l}\text { Length Rods } \\
\text { (nm) }\end{array}$ & $x$ & $\begin{array}{c}18.4 \pm \\
6.5 \\
(35 \%)\end{array}$ & $\begin{array}{c}21.3 \pm \\
7.9 \\
(37 \%)\end{array}$ & $\begin{array}{c}24.0 \pm \\
8.5 \\
(35 \%)\end{array}$ & $\begin{array}{c}32.6 \pm \\
12.0 \\
(37 \%)\end{array}$ \\
\hline $\begin{array}{l}\text { Diameter } \\
\text { Rods (nm) }\end{array}$ & $x$ & $\begin{array}{c}2.8 \pm \\
0.3 \\
(11 \%)\end{array}$ & $\begin{array}{c}2.2 \pm \\
0.3 \\
(14 \%)\end{array}$ & $\begin{array}{c}2.1 \pm \\
0.3 \\
(14 \%)\end{array}$ & $\begin{array}{c}2.7 \pm \\
0.3 \\
(11 \%)\end{array}$ \\
\hline \multicolumn{6}{|l|}{ Aspect Ratio } \\
\hline $\begin{array}{c}\text { (Length/ } \\
\text { Diameter) }\end{array}$ & $x$ & 6.6 & 9.6 & 11.4 & 12.1 \\
\hline
\end{tabular}

showing the disappearance of the NPs (Fig. S3†, S4 ${ }^{\dagger}$ and $\left.\mathrm{S}^{+}{ }^{+}\right){ }^{32}$

From these observations, we can hypothesize that a total or partial dissolution of the spherical NPs via an oxidative etching process may be involved before the growth of the NRs. Verily, oxidative etching was often proposed in literature and can be initiated by many chemical agents like chloride, oxygen or water traces in the reaction media. ${ }^{33-35}$ At this stage, we postulated that OAm would be able to offer a favorable environment to the growth of the Co NRs. Indeed, such a growing mechanism in a textured media containing OAm was already reported for the formation of gold nanowires and nanorods.36-39 To support these hypotheses, more precise information was collected and monitoring the reaction via in-situ measurements was considered.

Firstly, E-TEM in-situ analysis should help to really identify if an etching/dissolution occurs and secondly, pseudo in-situ SAXS measurement should give as global behavior of the reaction in terms of anisotropic evolution and textured media. E-TEM analysis was performed on a solution of the cobalt precursor [CoCl$\left.\left(\mathrm{PPh}_{3}\right)_{3}\right]$ dissolved in a mixture of solvents $(2 / 3 \mathrm{OAm}, 1 / 3$ toluene for solubility and viscosity reasons at room temperature). Micro-drops of solution were encapsulated between two graphene oxide layers, deposited on a carbon film, as described previously. ${ }^{40}$ These micro-drops were placed under the electron beam of E-TEM that also served as an energy supply, to induce the reaction even at room temperature (RT). From $1 \mathrm{~min}$ to $3 \mathrm{~min}$, the first cobalt nuclei appeared and the density of nuclei got higher (Fig. 2). When the reaction reached $19 \mathrm{~min}$, all the nuclei were dissolved and had disappeared. Suddenly at $23 \mathrm{~min}$, the growth of nanorods started with the formation of small metal nanowires, and they became longer in time $(38 \mathrm{~min}$ ). This E-TEM analysis showed that we had a dissolution of the spherical Co NPs which was confirmed using a real in-situ liquid cell (Protochips-Poseidon sample holder, Fig. $\left.\mathrm{S} 11^{\dagger}\right)$. Furthermore, after dissolution of the spherical NPs a separated phenomenon occurred with the formation of the NRs.

SAXS measurements were performed on a mixture of cobalt (I) precursor in two different OAm purities (70\% and $98 \%$ ) as a reference - Co NRs were synthesized in OAm 70\%, but in order to have a better overview of the possible effect of a texturing media by OAm, the measurement was also performed in OAm $98 \%$. To be homogeneous, the solutions were heated to $50^{\circ} \mathrm{C}$ for $10 \mathrm{~min}$ to enhance the dissolution of the complex without starting the disproportionation process (Fig. 3a). Irrespective of the purity of OAm, periodic peaks characteristic of a lamellarstructure were clearly observed at 1.26 and $2.52 \mathrm{~nm}^{-1}$. In the case of the OAm 98\%, the coherence length (ie FWHM) appears to be more important than in OAm $70 \%$, that can be explained by the presence of a large amount of shorter amino-chains and other impurities in this OAm. The periodic peaks corresponded to an inter-lamellar distance of $5 \mathrm{~nm}$ (for calculation, see $\mathrm{SI}$, eq. $\mathrm{S}^{+}+$and $\mathrm{S}_{2}+$ ) and indicate the presence of texturing media of the OAm probably complexed to the cobalt precursor. This result confirmed what were observed in the literature where an inter-lamellar distance between two nanowires of gold were measured at $4,8 \mathrm{~nm}$ with OAm. ${ }^{41}$ Akin to the kinetics study made by TEM, "pseudo in-situ" measurements were realized by collecting samples at different time intervals of the formation of the NRs (Fig. 3b). Using only OAm (70\%, 10mL). Even if the total fitting of the curves seemed to be complex due to the superposition of several contributions (OAm texture, spherical shape particles, rod shape particles, aggregation effect between particles), some elements could be extracted. The texturing peak was clearly present in all curves. The curves show a clear transition after $0.5 \mathrm{~h}$ in shape and organization. The position in $q$ of the transition from almost power law intensity at small $q$ to a dump zone at larger q shifted to low q with over time (dashed black arrow, Fig. 3b). In addition, the power law decreased in slope at the same time. This behavior indicates the growth of at least one dimension of these nano-objects and is in 

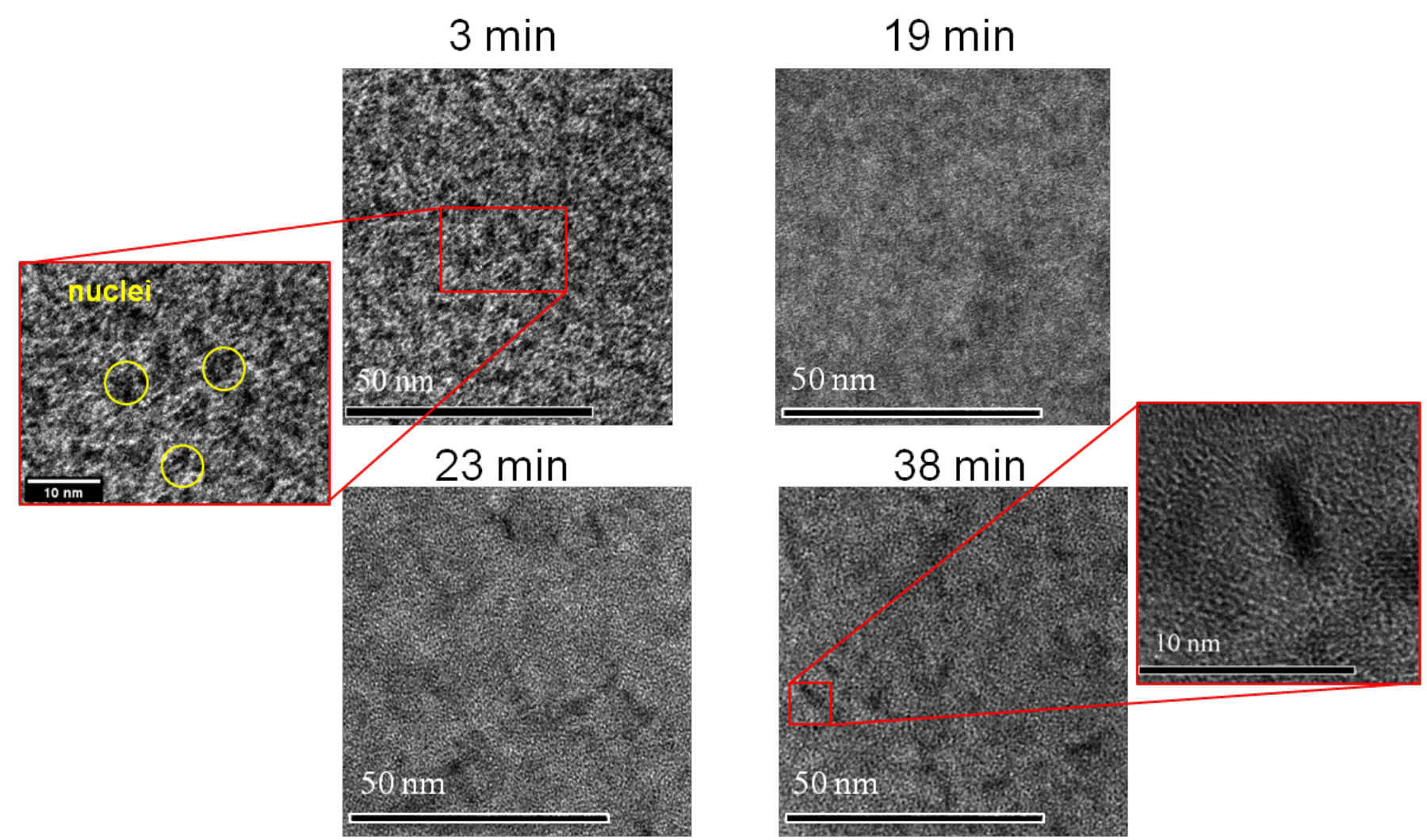

Fig. 2 E-TEM images of the nanospheres dissolution and the formation in-situ of the cobalt nanorods (zoom at 3min and 19min see S12t).

agreement with an anisotropic evolution of the NPs. The preexisting structuring did not seem to control the initial growth (presumably because the nucleation took place under the kinetic control too rapidly) but may influences the growth after the dissolution or etching which is a much slower phenomenon under thermodynamic control.

Albeit, if we clearly observed the dissolution of the NPs by E-TEM formed after $1 \mathrm{~h}$ and a further anisotropic growth in a possible OAm template, it remainded mandatory to clarify the mechanisms of the dissolution and the regrowth in NRs.

We first studied the phenomena involved in the reduction of the cobalt (II) complexes (blue-purple supernatant) resulting from the disproportionation process. In literature, several examples reported the reduction of metal complexes via their thermolysis to induce their reduction achieving the generation of nuclei. ${ }^{42}$ Experimentally, a batch of spherical Co NPs obtained after $1 \mathrm{~h}$ were heated for $9 \mathrm{~h}$ with a new fresh OAm. No shape transformation was noticed due to a heating nor over time (see $\mathrm{SI}$, Table S2 + , entry 9$)$. Then a batch of $\left[\mathrm{CoCl}_{2}\left(\mathrm{PPh}_{3}\right)_{2}\right]$ previously synthetized was solubilized in an unfunctionalized solvent such as tetradecane and heated up to $190^{\circ} \mathrm{C}$ for $10 \mathrm{~h}$ (see SI, Table $\mathrm{S} 2+$, entry 1 ). The initial blue color observed when the complex was dissolved remained, and no evidence of any transformations were noticed indicating that no reduction occurred by a thermolysis process. A similar reaction with OAm as a solvent gave similar results showing that the OAm reductant potential did not result to the reduction of $\left[\mathrm{CoCl}_{2}\left(\mathrm{PPh}_{3}\right)_{2-n}(\mathrm{OAm})_{n}\right]$. Two other tests preserving these conditions $\left(\mathrm{OAm}, 190^{\circ} \mathrm{C}, 10 \mathrm{~h}\right.$ and tetradecane, $\left.190^{\circ} \mathrm{C}, 10 \mathrm{~h}\right)$ were performed with the addition of spherical Co NPs. While in tetradecane no reaction was observed, in OAm the blue solution became colorless proving that the reduction of a cobalt (II) complex was accessible. It is important to highlight that the same test reaction at room temperature did not yield a similar result i.e the blue color remains. From these tests it appeared evident that this association of the spherical Co NPs, the OAm and a sufficient temperature was mandatory to induce the $\left[\mathrm{CoCl}_{2}\left(\mathrm{PPh}_{3}\right)_{2-n}(\mathrm{OAm})_{n}\right]$ reduction. During these last tests, even though observation was difficult due to the strong stirring, we also noticed an evolution of gas bubbles in the solution; we presumed the gas could be hydrogen. In fact, in literature, one is able to perform catalytic acceptorless dehydrogenation using cobalt NPs on N-heterocycles ${ }^{43-45}$ and primary allyl amines. ${ }^{46}$ This year, Beller et al. have established that this reactivity can be extended to primary alkyl amines. ${ }^{47}$ Thus, to trap the suspected hydrogen generation we considered a semihydrogenation reaction of carbon-carbon triple bond. 48 Previously we showed that our unsupported Co NPs were able to catalyze the reduction of alkyne to alkene in presence of hydrogen. ${ }^{49}$ Thus, we designed a specific setup in an $\mathrm{H}$-tube, formed by a glass link between two microwaves vials, and spherical Co NPs in OAm at $190^{\circ} \mathrm{C}$ were introduced on one side and spherical Co NPs with diphenylacetylene (DPA) were mixed in toluene on the other side at RT (Scheme 2). 
After ten hours, the solution containing DPA was filtered to remove metallic cobalt and analyzed using ${ }^{1} \mathrm{H}$ NMR. The ${ }^{1} \mathrm{H}$ NMR spectra confirmed the formation of stilbene and alkane
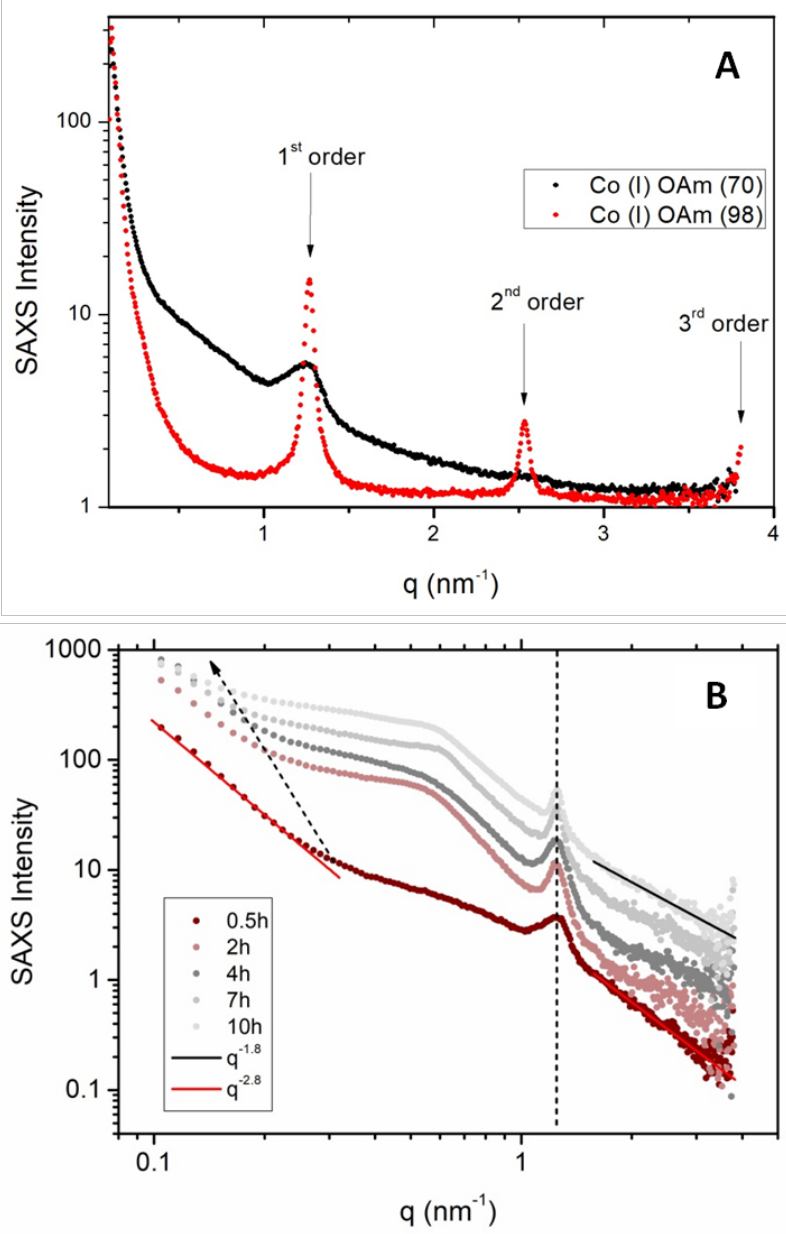

Fig. 3 SAXS measurement of a mixture of OAm and the cobalt precursor after 10 min at $50^{\circ} \mathrm{C}(\mathrm{A})$, SAXS "pseudo in-situ" measurement, collected at different time arrow for the border between low-q Porod domain and Guinier domain. All the curves have been vertically shifted to enhance clarity.

in $16 \%$ and $1 \%$ yield, respectively (Fig. $\mathrm{S} 13^{+}$). The hydrogen that was needed for hydrogenation was produced with the association of NPs and OAm. We decided to monitor the acceptorless dehydrogenation of OAm by collecting the generated gas with a sealed tube connected to an upside down graduated tube filled with water. The volume of gas collected was notified over time and compiled in a graph (Fig. 4).

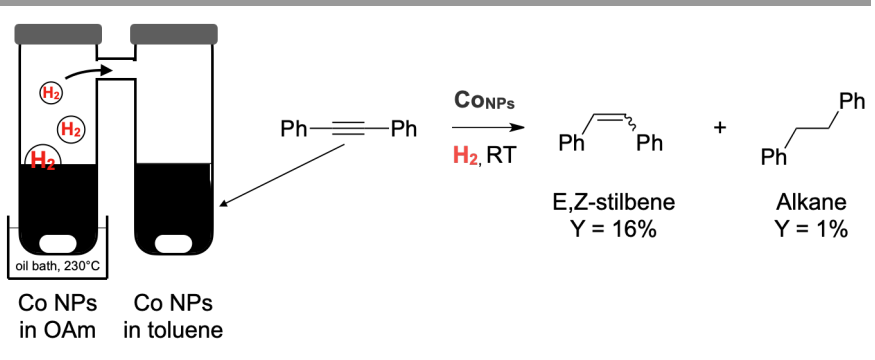

Scheme 2 Catalytic reduction in $\mathrm{H}$-tube of diphenylacetylene by hydrogen released from OAm in presence of cobalt

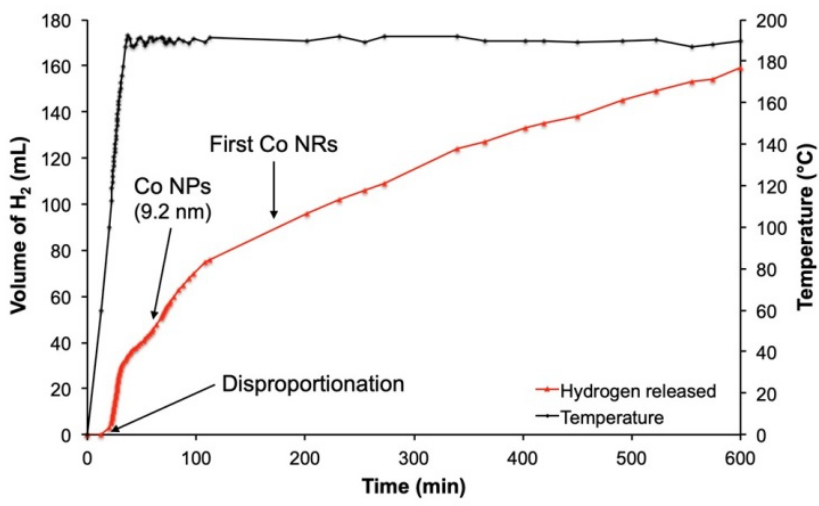

Fig. 4 Volume of gas collected over ten hours of reaction.

In this graph, we saw that the first hydrogen release took place after 20 minutes before the formation of Co NPs at $140^{\circ} \mathrm{C}$ as the temperature rose. The gas expansion overheating and the probable action of cobalt nuclei on the dehydrogenation of OAm explained the strong hydrogen flow observed at this stage, although the Co NPs were not formed. After $180 \mathrm{~min}$, the rate of hydrogen released decreased, suggesting that a lower catalytic activity of NRs compared to Co NPs may be involved, even if the gas released never stopped over the course of the reaction.

As previously mentioned, during the morphologic transformation from sphere to rods, the total consumption of $\left[\mathrm{CoCl}_{2}\left(\mathrm{PPh}_{3}\right)_{2-n}(\mathrm{OAm})_{n}\right]$ was observed. We just proved that hydrogen is generated in the process. In literature, hydrogen is known as an efficient reducing reagent allowing the formation of metal (0) from organometallic precursors. For instance, Chaudret et al. published the synthesis of cobalt nano-objects via the reduction of cobalt (I) or cobalt (II) complexes (respectively [Co $\left.\left(\eta^{3}-\mathrm{C}_{8} \mathrm{H}_{13}\right)\left(\eta^{4}-\mathrm{C}_{8} \mathrm{H}_{12}\right)\right]$ and $\left.\left[\mathrm{Co}\left\{\mathrm{N}\left(\mathrm{SiMe}_{3}\right)_{2}\right\}_{2}\right]\right)$ under 3 bar of $\mathrm{H}_{2 .}{ }^{6,17}$ Experimentally, we considered a sealed tube containing $\mathrm{OAm}$ and $\left[\mathrm{CoCl}_{2}\left(\mathrm{PPh}_{3}\right)_{2}\right]$, under $\mathrm{H}_{2}$. Subsequently, the solution was heated for 10 hours at $190^{\circ} \mathrm{C}$ under magnetic stirring (Scheme 3, Fig. S18' and S19†).

The solution, initially dark blue, turned colorless with a white-pink salt in suspension, which was isolated and characterized by ${ }^{1} \mathrm{H}$ NMR as ammonium chloride derivative of OAm (Fig. S14 ${ }^{\dagger}$ ). More importantly, a black magnetic powder was deposited on the stirring bar. It clearly appeared that the presence of a hydrogen atmosphere achieved to the reduction of cobalt (II) salt giving the formation of metallic cobalt following a redox process. 

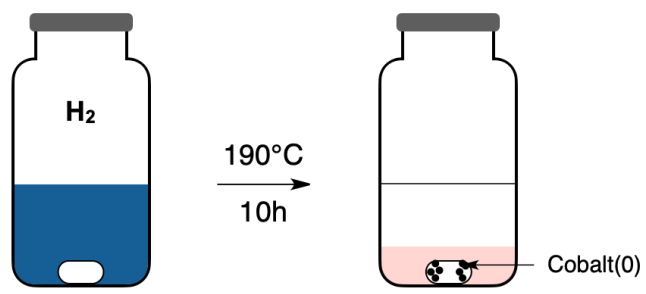

$\mathrm{CoCl}_{2}\left(\mathrm{PPh}_{3}\right)_{2}$ in Oleylamine

Scheme 3 Evolution of the solution's color under $\mathrm{H}_{2}$ atmosphere before and after heating (Fig. S18' and S19').

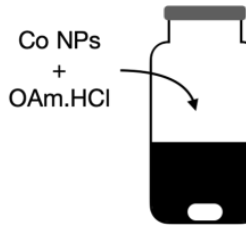

$t_{0}, 23^{\circ} \mathrm{C}$

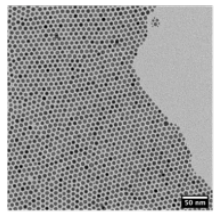

$\mathrm{d}=8.5 \pm 0.8 \mathrm{~nm}(9 \%) \quad \mathrm{d}=8.3 \pm 2.1 \mathrm{~nm}(25 \%) \quad \mathrm{d}=6.2 \pm 1.2 \mathrm{~nm}(19 \%)$

$2 \mathrm{X}_{7}>\mathrm{NH}_{7} \mathrm{NH}_{3}+\mathrm{Cl}^{-}+$

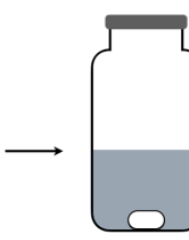

$\mathrm{t}_{15 \min }, 78^{\circ} \mathrm{C}$

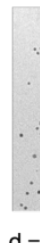

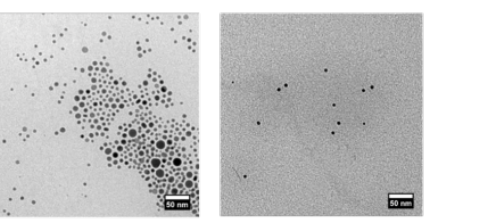

Co $\longrightarrow 2 \mathrm{H}_{7}-\mathrm{NH}_{7}+\mathrm{CoCl}_{2}+\mathrm{H}_{2}$

Scheme 4 Evolution of Co NPs in presence of $\mathrm{OAm}$. $\mathrm{HCl}$ in $\mathrm{OAm}$ heated with a ramp of $230^{\circ} \mathrm{C}$ /hour. TEM images at $\mathrm{t}=0 \mathrm{~min}, 15 \mathrm{~min}$ and $30 \mathrm{~min}\left(\mathrm{Fig} . \mathrm{S} 17^{+}\right.$).

The concomitant formation of the ammonium chloride derivative of OAm (OAm. $\mathrm{HCl})$ was the result of an acid/base reaction between $\mathrm{OAm}$ and $\mathrm{HCl}$. This reaction was probably the driving force in the reduction of cobalt (II) salts and inhibited the back reaction (addition of $\mathrm{HCl}$ on Co) which is thermodynamically favored. As previously stated, the experimental observation monitored by E-TEM suggested that the spheres appeared at early age of the reaction, and were dissolved and finally regrew as nanorods in a textured media. In countless publications, chloride salts were described as efficient candidates to induce etching pathway, a classical route to dissolve NPs. ${ }^{50-52}$ Consequently, it appeared interesting to evaluate the impact of $\mathrm{OAm} . \mathrm{HCl}$ generated in-situ of the spherical Co NPs. Thus, OAm. $\mathrm{HCl}$ was separately synthesized and added to a solution of Co NPs in OAm. Then, the solution was heated up to $190^{\circ} \mathrm{C}$ under magnetic stirring (Scheme 4).

After 15 minutes, the color of the solution changed from black to gray with blue hints and 15 minutes later, the solution was totally blue, the characteristic color of $\left[\mathrm{CoCl}_{2}\left(\mathrm{PPh}_{3}\right)_{2}\right.$ $\left.{ }_{n}(\mathrm{OAm})_{\mathrm{n}}\right]$ salt obtained after the disproportionation. TEM pictures collected at 15 and $30 \mathrm{~min}$ showed that the amount of Co NPs decreased as much as their diameters, whereas their polydispersity increased. These observations are characteristic of an oxidative etching process, where anionic chlorides react with cobalt atoms on the surface of NPs to give $\mathrm{CoCl}_{2}$ salts and release hydrogen (equation, Scheme 4). It is important to notify that the clear blue solution was obtained during the rise in temperature at only $140^{\circ} \mathrm{C}$, that is, that the disappearance of NPs should be even faster in the conditions of NRs formation $\left(190^{\circ} \mathrm{C}\right)$. In brief, macroscopic observations pointed out that the morphological transition is concomitant with a total reduction of cobalt (II) complexes which were by-product of the disproportionation. Through an autocatalysis reaction, four major steps were identified: i) the dehydrogenation of OAm that produced hydrogen, ii) which was used as a reducing agent reacting with $\left[\mathrm{CoCl}_{2}\left(\mathrm{PPh}_{3}\right)_{2-n} \mathrm{OAm}_{\mathrm{n}}\right]$ to give cobalt nuclei and $\mathrm{HCl}$, iii) via an acid-base reaction $\mathrm{HCl}$ and $\mathrm{OAm}$ formed the ammonium chlorine derivatives, $\mathrm{OAm} . \mathrm{HCl}$, iv) this chlorine salt served as an etching agent inducing the loss of initial Co NPs to generate a cobalt (II) complex, closing the catalytic cycle loop. All these steps were linked and interdependent and a catalytic cycle can be proposed (Scheme 5).

Scheme 5. Proposal mechanism for the morphological transition from Co NPs to Co NRs. 


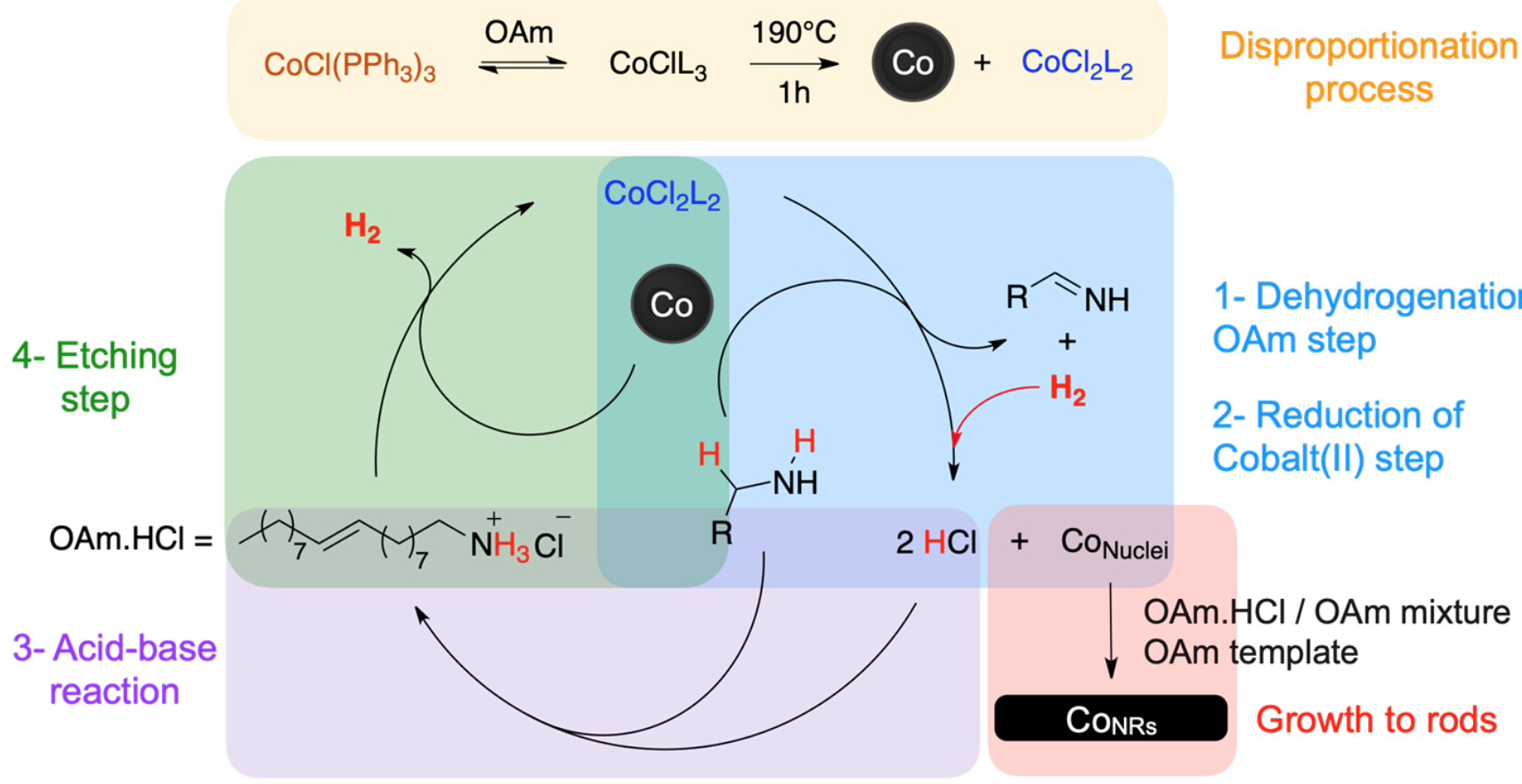

amine dehydrogenation, showing the importance of primary amine to induce the catalytic cycle leading to Co rods. As observed earlier, hydrogen was generated continually, that is,

With this approach, the contribution in the formation of Co $\mathrm{NRs}$ is not only provided by the reduction of $\left[\mathrm{CoCl}_{2}\left(\mathrm{PPh}_{3}\right)_{2}\right.$ ${ }_{n}(\mathrm{OAm})_{\mathrm{n}}$ ] but also by the Co NPs initially formed, both having acted as a "cobalt reservoir". These two steps slowly produced cobalt atoms and the growth of further nano-objects was managed under thermodynamic control. Finally, not only acting as hydrogen source or an etching agent, OAm under its protonated form (OAm. $\mathrm{HCl}$ ) also played a role in the anisotropic growth of the NRs. Indeed, it was established that ionic surfactants are preferentially adsorbed on the (100) facets orientated the growth along the $\mathrm{c}$ axis. ${ }^{53}$

Whether the extension to other amines under the same synthesis conditions would have an influence on the behavior of the objects formed was investigated. First, other fatty amines (containing from 8 to 18 carbon atoms, C8 to C18) were tested. With $\mathrm{C} 8$, the presence of a set of small particles was noted. For C12 and C14 amines, a double population of sticks and spheres were observed. In the case of C16 and C18 amines, the majority of NRs were formed. This was in line with the literature where it was shown that for gold NRs, when the length of the alkyl chain increased, the formation of NRs was more important. ${ }^{54}$ It was therefore shown that the formation of NRs was driven by other primary amines. Secondly, to point out the key role of primary amines in the mechanism, a reaction was made with $\mathrm{N}, \mathrm{N}$-dimethylhexadecylamine. After $10 \mathrm{~h}$, a magnetic powder consisting of various sizes and high polydispersity Co nanoobjects was observed by TEM with a blue supernatant above them (Fig. S6+). This substitution did not avoid the disproportionation process to occur, however, as expected, no reduction of the cobalt (II) was noticed. Undoubtely, the presence of methyl groups on the nitrogen atom prevented the
OAm should be available along the reaction for acceptorless dehydrogenation. Thereby the amount of amine in the reaction was crucial to perform the reaction but also as a surfactant.

Experimentally, $\left[\mathrm{CoCl}\left(\mathrm{PPh}_{3}\right)_{3}\right]$ was heated at $190^{\circ} \mathrm{C}$ for $10 \mathrm{~h}$ in a mixture of tetradecane and OAm with a 9:1 ratio respectively and monitored by TEM and SAXS measurements (Fig. 5). After 10h, a large majority of spherical NPs did not evolve in shape (compare to $1 \mathrm{~h}$, see $\mathrm{SI}$ Fig. $\mathrm{ST}^{+}$) and only a small percentage of cobalt was converted to NRs. Moreover, the supernatant after treatment was blue, indicating that a full reduction of cobalt(II) was not achieved. These observations were confirmed by SAXS analysis where once the particles have formed (2h) no structuring peaks were observed; the curves did not changed, thus indicated only the presence of spheres, the too little amount of rods was not significant for observation. The simulation of the curves indicated an average particle size of 8$8.5 \mathrm{~nm}$, which was close to the values found by TEM $[8.3 \pm 1.5$ $\mathrm{nm}(15 \%)]$. The slope of the decrease in intensity at large $\mathrm{q}$ is almost in $\mathrm{q}^{-4}$. This indicated that the particles were not aggregated according to the TEM images. Interestingly, when the alkane/amine ratio increased to $7: 3$, the presence of NRs was clearly observed after five hours. Nevertheless, even after 

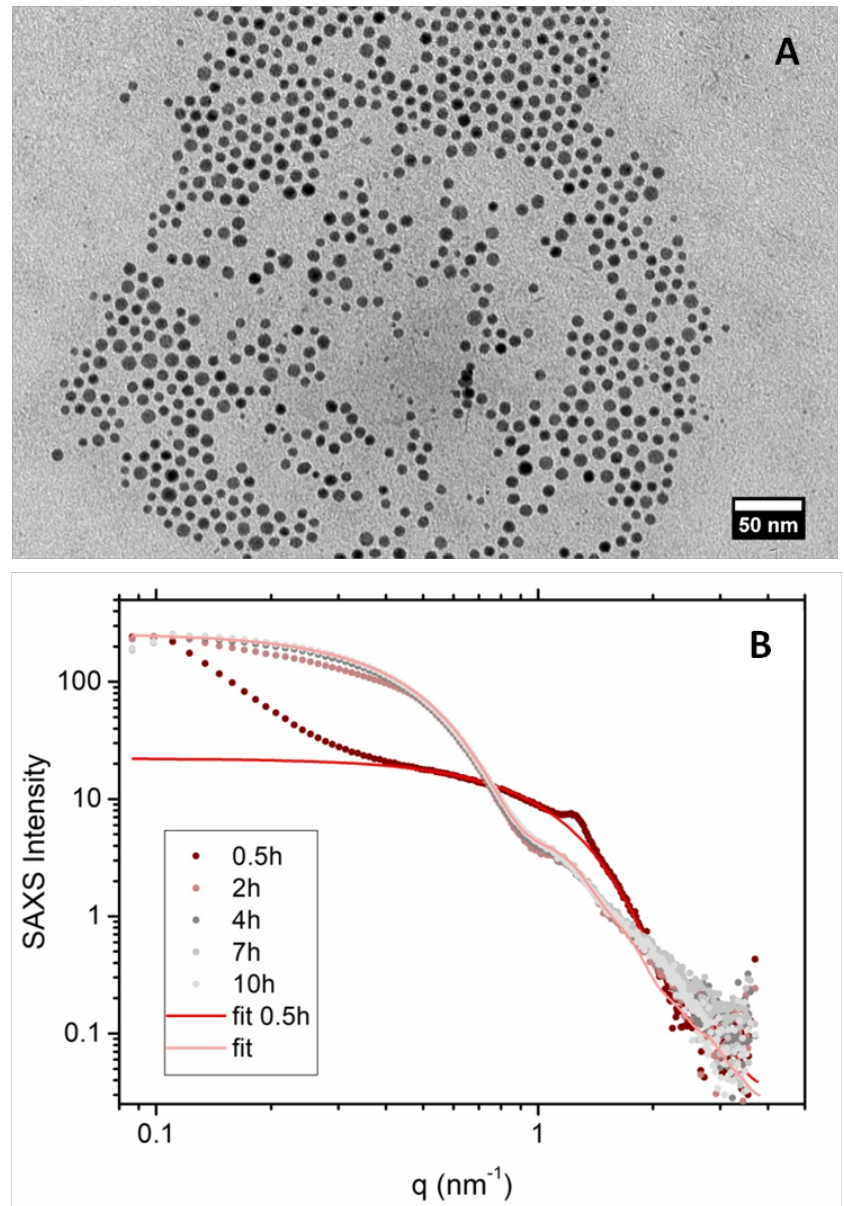

Fig. 5. TEM picture of Co NPs synthesis at $10 \mathrm{~h}$ in a mixture of Tetradecane/OAm (ratio 9:1) (A). SAXS "pseudo in-situ" measurement, collected at different time intervals, a mixture of Tetradecane/OAm (ratio 9:1) (B).

15 hours, nanospheres remained (Fig. S9t). Consequently, it appears that: i) the amount of OAm was able to control the kinetic of the reaction; ii) a minimum of OAm was imperative to maintain a reductive atmosphere allowing the morphological transition.

It was established that similar spherical cobalt NPs can be obtained with bromine and iodine complex derivatives using the same redox pathway. ${ }^{25,49}$ In literature, it is also mentioned that bromine ${ }^{55,56}$ and on rare occasions iodine ${ }^{57}$ were able to induce oxidative etching allowing the production of Co NRs through a similar mechanism. [CoBr $\left.\left(\mathrm{PPh}_{3}\right)_{3}\right]$ and $\left[\mathrm{Col}\left(\mathrm{PPh}_{3}\right)_{3}\right]$ were synthesized and Co NRs were obtained after $10 \mathrm{~h}$ and $18 \mathrm{~h}$, respectively (Fig. S10+). The Co NRs from the iodine complex had a shape similar to those obtained with $\left[\mathrm{CoCl}\left(\mathrm{PPh}_{3}\right)_{3}\right]$ with an average length of $22.4 \pm 4.5 \mathrm{~nm}(20 \%)$. In this case, the NRs exhibit a spontaneous organization that has rarely been seen in literature. ${ }^{57}$ This type of arrangement can be explained by the much slower kinetics within the framework of the iodine complex. In the case of bromine, NRs were also observed after $10 \mathrm{~h}$ but their shapes and sizes were dissimilar (polydispersity) with the presence of nanowires. However, it was noted that the kinetics were different in the context of iodine ( $3 \mathrm{~h}$ instead of 1h) and could be explained by the disproportionation energies, which were different and in particular higher for iodine $(22.7$ and $25.0 \mathrm{kcal}^{\mathrm{mol}}{ }^{-1}$ for chlorine and bromine, $27.1 \mathrm{kcal} . \mathrm{mol}^{-1}$ for iodine). ${ }^{25}$ This difference in kinetics was also verified for the formation of NRs where iodine exhibits longer kinetics than for chlorine and bromine.

\section{Conclusions}

In sum, we present here a chemical explanation of a morphological transition from Co NPs to Co NRs. Indeed, after an initial disproportionation step promoted by OAm interaction with the cobalt(I), in-situ measurements as E-TEM and SAXS and kinetic study (TEM) were allowed to identify, for the first step, a dissolution of the Co NPs and, secondly, a re-growth of nuclei generated in a OAm template. It was also proved that hydrogen was released promoted by acceptorless dehydrogenation of OAm catalyzed by Co NPs. In addition, the released hydrogen caused the reduction of the by-product of the disproportionation i.e. cobalt (II). As suggested in literature, experiments confirm that an oxidative etching of the Co NPs by this chlorine salts took place, providing a second source of cobalt nuclei. Contrary to the kinetic conditions involved in the early formation of spherical Co NPs, the nuclei were generated under thermodynamic conditions in an $\mathrm{OAm} . \mathrm{HCl}$ and $\mathrm{OAm}$ texturized mixture inducing anisotropic regrowth. Interestingly, in the recent paper published by Viau et al. (Scheme 1, green square), ${ }^{22}$ the authors suggested that the released hydrogen may acted as a reductant in the reduction of cobalt at the surface of noble metal seeds. Our results developed in this publication, proved that the hydrogen in-situ generated allowed the reduction of cobalt salts. We believe that this paper will provide answers not only to the morphological transition study of previous mechanisms, but also to future mechanisms on the transformation of nano-objects, albeit for cobalt or other metals.

\section{Conflicts of interest}

There are no conflicts to declare.

\section{Acknowledgements}

This work was financially supported by Sorbonne Université, CNRS, the French National Research (ANR) in the framework of the its NUMEN program under reference ANR- 17-CE09-0037 and LabEx MiChem ("Investissements d'Avenir" program) under reference ANR-11-IDEX-0004-02. The authors would like to acknowledge support from the International Research Network-IRN “Nanoalloys" of CNRS.

\section{Notes and references}

1 S. M. Bhagyaraj, O. S. Oluwafemi, N. Kaleikkal and S. Thomas, Applications of Nanomaterials, Woodhead Publishing, 2018.

2 L. Shang, S. Dong and G. U. Nienhaus, Nano Today, 2011, 6, 401418. 
3 H. Xie, T. Wang, J. Liang, Q. Li and S. Sun, Nano Today, 2018, 21, 41-54.

4 Y. Wu, M. R. K. Ali, K. Chen, N. Fang and M. A. El-Sayed, Nano Today, 2019, 24, 120-140.

5 N. T. K. Thanh and L. A. W. Green, Nano Today, 2010, 5, 213-230.

6 N. Liakakos, B. Cormary, X. Li, P. Lecante, M. Respaud, L. Maron, A. Falqui, A. Genovese, L. Vendier, S. Koïnis, B. Chaudret and K. Soulantica, J. Am. Chem. Soc., 2012, 134, 17922-17931.

7 D. Lisjak and A. Mertelj, Prog. Mater. Sci., 2018, 95, 286-328.

8 K. Thorkelsson, P. Bai and T. Xu, Nano Today, 2015, 10, 48-66.

9 S. Ener, E. Anagnostopoulou, I. Dirba, L. M. Lacroix, F. Ott, T. Blon, J. Y. Piquemal, K. P. Skokov, O. Gutfleisch and G. Viau, Acta Mater. 2018, 145, 290-297.

10 J. D. Carter, G. Cheng and T. Guo, J. Phys. Chem. B, 2004, 108, 6901-6904.

11 H. T. Yang, C. M. Shen, Y. K. Su, T. Z. Yang, H. J. Gao and Y. G. Wang, Appl. Phys. Lett., 2003, 82, 4729-4731.

12 J. X. Liu, H. Y. Su, D. P. Sun, B. Y. Zhang and W. X. Li, J. Am. Chem. Soc., 2013, 135, 16284-16287.

13 A. Viola, J. Peron, M. Giraud, L. Sicard, A. Chevillot-Biraud, P. Decorse, S. Nowak, P. Beaunier, P. Lang and J. Y. Piquemal, J. Colloid Interface Sci., 2020, 573, 165-175.

14 Y. Wang, X. Yang, G. Xiao, B. Zhou, B. Liu, G. Zou and B. Zou, CrystEngComm, 2013, 15, 5496-5505.

15 E. Ringe, R. P. Van Duyne and L. D. Marks, J. Phys. Chem. C, 2013, $117,15859-15870$

16 S. F. Tan, G. Bisht, U. Anand, M. Bosman, X. E. Yong and U. Mirsaidov, J. Am. Chem. Soc., 2018, 140, 11680-11685.

17 F. Dumestre, B. Chaudret, C. Amiens, M. Respaud, P. Fejes, P. Renaud and P. Zurcher, Angew. Chem., Int. Ed., 2003, 42, 5213-5216.

18 F. Dumestre, B. Chaudret, C. Amiens, M. C. Fromen, M. J. Casanove, P. Renaud and P. Zurcher, Angew. Chem., Int. Ed., 2002, 41, 4286-4289.

19 B. Cormary, T. Li, N. Liakakos, L. Peres, P. F. Fazzini, T. Blon, M. Respaud, A. J. Kropf, B. Chaudret, J. T. Miller, E. A. Mader and K. Soulantica, J. Am. Chem. Soc., 2016, 138, 8422-8431.

20 Y. Soumare, J. Y. Piquemal, T. Maurer, F. Ott, G. Chaboussant, A. Falqui and G. Viau, J. Mater. Chem., 2008, 18, 5696-5702.

21 K. Ait Atmane, F. Zighem, Y. Soumare, M. Ibrahim, R. Boubekri, T. Maurer, J. Margueritat, J. Y. Piquemal, F. Ott, G. Chaboussant, F. Schoenstein, N. Jouini and G. Viau, J. Solid State Chem., 2013, 197, 297-303.

22 R. K. Ramamoorthy, A. Viola, B. Grindi, J. Peron, C. Gatel, M. Hytch, R. Arenal, L. Sicard, M. Giraud, J. Y. Piquemal and G. Viau, Nano Lett., 2019, 19, 9160-9169.

23 K. A. Atmane, C. Michel, J. Y. Piquemal, P. Sautet, P. Beaunier, M. Giraud, M. Sicard, S. Nowak, R. Losno and G. Viau, Nanoscale, 2014, 6, 2682-2692.
24 S. Mourdikoudis and L. M. Liz-Marzán, Chem. Mater., 2013, 25 , 1465-1476.

25 A. Vivien, M. Guillaumont, L. Meziane, C. Salzemann, C. Aubert, S. Halbert, H. Gérard, M. Petit and C. Petit, Chem. Mater., 2019, 31 960-968.

26 L. Meziane, C. Salzemann, C. Aubert, H. Gérard, C. Petit and M. Petit, Nanoscale, 2016, 8, 18640-18645.

27 J. M. Yuk, J. Park, P. Ercius, K. Kim, D. J. Hellebusch, M. F. Crommie, J. Y. Lee, A. Zettl and A. P. Alivisatos, Science (80-. )., 2012, 335, 61-64.

28 H. Zheng, R. K. Smith, Y. W. Jun, C. Kisielowski, U. Dahmen and A. Paul Alivisatos, Science (80-. )., 2009, 324, 1309-1312.

29 T. Li, A. J. Senesi and B. Lee, Chem. Rev., 2016, 116, 11128-11180.

30 B. Abécassis, F. Testard, O. Spalla and P. Barboux, Nano Lett., 2007, 7, 1723-1727.

31 A. Henkel, O. Schubert, A. Plech and C. Sönnichsen, J. Phys. Chem. C, 2009, 113, 10390-10394.

32 Same Studies Have Been Conducted in the Raw Medium with a Direct Deposition on the TEM Grids and Concluded at the Same Results.

33 R. Long, S. Zhou, B. J. Wiley and Y. Xiong, Chem. Soc. Rev., 2014, 43, 6288-6310.

34 Y. Zheng, J. Zeng, A. Ruditskiy, M. Liu and Y. Xia, Chem. Mater., 2014, 26, 22-33.

35 H. Guo, Y. Chen, H. Ping, L. Wang and D. L. Peng, J. Mater. Chem., 2012, 22, 8336-8344.

36 Z. Huo, C. K. Tsung, W. Huang, X. Zhang and P. Yang, Nano Lett., 2008, 8, 2041-2044.

37 Z. Li, J. Tao, X. Lu, Y. Zhu and Y. Xia, Nano Lett., 2008, 8, 30523055 .

38 X. Lu, M. S. Yavuz, H. Y. Tuan, B. A. Korgel and Y. Xia, J. Am. Chem. Soc., 2008, 130, 8900-8901.

39 J. Zeng, Y. Ma, U. Jeong and Y. Xia, J. Mater. Chem., 2010, 20, 2290-2301.

40 A. De Clercq, W. Dachraoui, O. Margeat, K. Pelzer, C. R. Henry and S. Giorgio, J. Phys. Chem. Lett., 2014, 5, 2126-2130.

41 A. Loubat, L. M. Lacroix, A. Robert, M. Impéror-Clerc, R. Poteau, L. Maron, R. Arenal, B. Pansu and G. Viau, J. Phys. Chem. C, 2015, 119, 4422-4430.

42 V. F. Puntes, K. M. Krishnan and A. P. Alivisatos, Science (80-. )., 2001, 291, 2115-2117.

43 G. Jaiswal, M. Subaramanian, M. K. Sahoo and E. Balaraman, ChemCatChem, 2019, 11, 2449-2457.

44 C. Liao, X. Li, K. Yao, Z. Yuan, Q. Chi and Z. Zhang, ACS Sustain. Chem. Eng., 2019, 7, 13646-13654.

45 A. V. losub and S. S. Stahl, Org. Lett., 2015, 17, 4404-4407. 
46 F. Bottaro, A. Takallou, A. Chehaiber and R. Madsen, European J. Org. Chem., 2019, 2019, 7164-7168.

47 X. Cui, W. Li, K. Junge, Z. Fei, M. Beller, P. J. Dyson, Angew. Chem., Int. Ed. 2020, 2-9.

48 F. Chen, C. Kreyenschulte, J. Radnik, H. Lund, A. E. Surkus, K. Junge, M. Beller, ACS Catal. 2017, 7, 1526-1532.

49 A. Sodreau, A. Vivien, A. Moisset, C. Salzemann, C. Petit and M. Petit, Inorg. Chem., 2020, 59, 13972-13978.

50 L. Ma, C. Wang, M. Gong, L. Liao, R. Long, J. Wang, D. Wu, W. Zhong, M. J. Kim, Y. Chen, Y. Xie and Y. Xiong, ACS Nano, 2012, 6, 9797-9806.

51 B. Li, R. Long, X. Zhong, Y. Bai, Z. Zhu, X. Zhang, M. Zhi, J. He, C. Wang, Z. Y. Li and Y. Xiong, Small, 2012, 8, 1710-1716.

52 M. Jin, G. He, H. Zhang, J. Zeng, Z. Xie and Y. Xia, Angew. Chemie - Int. Ed., 2011, 50, 10560-10564.

53 M. S. Bakshi, Cryst. Growth Des. 2016, 16, 1104-1133.

54 J. Gao, C. M. Bender and C. J. Murphy, Langmuir, 2003, 19, 90659070.

55 B. J. Wiley, Y. Xiong, Z. Y. Li, Y. Yin and Y. Xia, Nano Lett., 2006, 6, 765-768.

56 B. J. Wiley, Y. Chen, J. M. McLellan, Y. Xiong, Z. Y. Li, D. Ginger and Y. Xia, Nano Lett., 2007, 7, 1032-1036.

57 M. A. Boles, M. Engel and D. V. Talapin, Chem. Rev., 2016, 116, 11220-11289. 